\title{
HUBUNGAN KELEBIHAN JAM KERJA DENGAN KEJADIAN HIPERTENSI PADA PEKERJA PT. ASTORIA BANGUN PERKASA BATAM
}

\author{
Saiful Batubara ${ }^{1}$, Lady Tria Rannie ${ }^{2}$, dan Rusdani ${ }^{2}$ \\ Email: Saifulbatubara24@gmail.com \\ ${ }^{1}$ Fakultas Kedokteran Universitas Islam Sumatera Utara \\ ${ }^{2}$ Fakultas Kedokteran Universitas Batam
}

\begin{abstract}
Background: This study aims to determine the relationship of excess working hours with the incidence of hypertension in PT. Astoria Build Mighty Batam.

Methods: This research method uses quantitative types with observational analytic research designs and Cross Sectional approaches. The population of this research is all PT. Astoria Bangun Perkasa which amounts to 60 workers. The instruments used in data retrieval are the Sphygmomanometer, the stethoscope and company data.

Results: The results of the univariate analysis showed that most workers experienced overtime hours of 17 people (34\%) while workers who did not experience excess hours worked as many as 33 people (66\%). Workers who experienced hypertension were 7 people (14\%) while workers who did not have hypertension were 43 people (86\%). The results of the bivariate analysis with the chi-square test showed that there was a significant relationship between excess work hours and hypertension.
\end{abstract}

Keywords: Excessive work hours and hypertension

\section{PENDAHULUAN}

Hipertensi atau tekanan darah tinggi adalah peningkatan tekanan darah sistolik lebih dari $140 \mathrm{mmHg}$ dan tekanan darah diastolik lebih dari 90 $\mathrm{mmHg}$ (Bakri, 2008). Ada 2 macam hipertensi, yaitu hipertensi primer dan hipertensi sekunder. $90 \%$ dari semua kasus hipertensi adalah primer. Tidak ada penyebab yang jelas tentang hipertensi primer, sekalipun ada beberapa teori yang menunujukkan adanya faktor-faktor genetik, perubahan hormon dan perubahan simpatis. Hipertensi sekunder adalah akibat dari penyakit atau gangguan tertentu (Baradero, 2008).

Berdasarkan hasil pengukuran tekanan darah, prevalensi hipertensi pada penduduk umur 18 tahun ke atas tahun 2007 di Indonesia adalah sebesar $31,7 \%$. Menurut provinsi, prevalensi hipertensi tertinggi di Kalimantan Selatan $(39,6 \%)$ dan terendah di Papua
Barat (20,1\%). Sedangkan jika dibandingkan dengan tahun 2013 terjadi penurunan sebesar $5,9 \%$ (dari $31,7 \%$ menjadi $25,8 \%$ ). Penurunan ini bisa terjadi berbagai macam faktor, seperti alat pengukur tensi yang berbeda, masyarakat yang sudah mulai sadar akan bahaya penyakit hipertensi. Prevalensi tertinggi di Provinsi Bangka Belitung $(30,9 \%)$, dan Papua yang terendah $(16,8) \%$. Prevalensi hipertensi di Indonesia yang didapat melalui kuesioner terdiagnosis tenaga kesehatan sebesar 9,4 persen, yang didiagnosis tenaga kesehatan atau sedang minum obat sebesar 9,5 persen. Jadi, ada 0,1 persen yang minum obat sendiri (Pusat Data dan Informasi Kementerian Kesehatan RI,2014).

Berdasarkan profil Dinas Kesehatan Kota Batam Tahun 2014 pasien hipertensi sebanyak 7.492 
orang yang didapatkan dari hasil distribusi kejadian hipertensi berdasarkan puskesmas yang tersebar tahun 2014 diantaranya : puskesmas Batu Aji sebesar 3,67\%, puskesmas Baloi Permai sebesar 3,59\%, puskesmas Sei Panas sebesar 3,12\%, puskemas Botania sebesar 3,35\%, dan puskesmas Lubuk Baja sebesar 3,5\% (Dinas Kesehatan Batam, 2014).

Menurut healthcare specialists at UCSF Medical Centre, faktor resiko penyebab hipertensi, antara lain : (1) Merokok,(2) Obesitas, (3) Stres, (4) Konsumsi garam, (5) Konsumsi alkohol.

Beberapa studi Jepang telah menemukan hubungan positif antara jam kerja yang panjang dan hipertensi. Hayashi dkk menunjukkan bahwa pengukuran tekanan darah rawat jalan (baik sistolik dan diastolik) pekerja dengan 88 jam lembur per bulan secara signifikan lebih tinggi daripada orangorang yang bekerja hanya 25 jam per bulan (American Heart Association, 2006).

Jam kerja adalah waktu untuk melakukan pekerjaan, dapat dilaksanakan siang hari dan/atau malam hari. Jam kerja bagi para pekerja disektor swasta diatur dalam Undang-Undang No.13 tahun 2003 tentang ketenagakerjaan, khususnya pasal 77 sampai dengan pasal 85.

Waktu kerja lembur adalahwaktu kerja yang melebihi 7 jamsehari untuk 6 hari kerja dan 40 jamdalam seminggu atau 8 jam sehariuntuk 5 hari kerja dan 40 jam dalamseminggu atau waktu kerja pada hariistirahat mingguan dan atau pada harilibur resmi yang ditetapkanpemerintah (Pasal 1 ayat 1 PeraturanMenteri

No.102/MEN/VI/2004). Waktu kerja lembur hanya dapat dilakukan paling banyak 3 jam/hari dan 14 jam dalam 1 minggu diluar istirahat mingguan atau hari libur resmi.

Menurut penelitian di California, pekerja yang bekerja selama 40 jam per minggu memiliki kemungkinan $15 \%$ terjadi hipertensi (American Heart Association, 2006). Pekerja di PT. Astoria Bangun Perkasa Batam memiliki waktu kerja yang >7 jam/hari yang berpotensi mengalami stress dan mempunyai kebiasaan merokok sehingga dapat mengakibatkan hipertensi. Oleh sebab itu penulis tertarik untuk melakukan penelitian dengan judul "Hubungan kelebihan jam kerja dengan kejadian hipertensi pada pekerja di PT. Astoria Bangun Perkasa Batam pada tahun2018".

\section{METODE PENELITIAN}

Jenis penelitian yang di gunakan dalam penelitian ini adalah penelitian Kuantitatif, Penelitian ini menggunakan desain cross sectional yaitu jenis penelitian dengan cara pengambilan data variabel bebas dan variabel terikat dilakukan sekali waktu pada saat yang bersamaan.

Penelitian ini dilakukan pada bulan Agustus di PT. Astoria Bangun Perkasa Batam Tahun 2018 yang berlokasi di Jl. Tunas 2, No. 3A - 3D Batam centre. Populasi yang diambil pada penelitian ini adalah pekerja PT. Astoria Bangun Perkasa Tahun 2018 sebanyak 60 orang. Penelitian dilakukan pada 50 pekerja yang dipilih menjadi sampel berdasarkan tabel Isaac dan Michael dengan taraf kesalahan $5 \%$. Instrument yang digunakan dalam pengambilan data adalah Sfigmomanometer, stetoskop dan data perusahaan. Hasil penelitian dianalisis dengan distribusi frekuensi ditabulasi silang kemudian diuji dengan ujiChi-square.

\section{HASIL PENELITIAN \\ Gambaran Umum Lokasi Penelitian}

PT. Astoria Bangun Perkasa adalah perusahaan yang bergerak dalam bidang konstruksi yang berlokasi di Tunas 2, No. 3A - 3D Batam centre.PT ini berdiri sejak 
tahun 2011 dengan jumlah pekerja pada saat sekarang sebanyak 60 orang, yang terdiri dari 35 orang pekerja tetap dan 25 orang pekerja outsourcing.Pekerja PT. Astoria Bangun Perkasa bekerja dari pukul 08:00 sampai pukul 18:00 wib dengan waktu istirahat selama 1 jam dan pekerja bekerja setiap hari.

\section{Tabel.4.1 Distribusi Kejadian} Hipertensi.

\begin{tabular}{|l|c|c|}
\hline Kejadin HT & Jumlah & $\begin{array}{c}\text { Persentase } \\
(\%)\end{array}$ \\
\hline $\begin{array}{c}\text { Tdk } \\
\text { Hipertensi }\end{array}$ & 43 & 86 \\
\hline Hipertensi & 7 & 14 \\
\hline Total & 50 & 100 \\
\hline
\end{tabular}

Berdasarkan Tabel 4,4 diatas diketahui bahwa sebanyak 43 orang (86\%) responden tidak mengalami hipertensi dan 7 orang (14\%) mengalami hipertensi

\section{Tabel 4.2 Distribusi Frekuensi Kelebihan Jam Kerja}

\begin{tabular}{|c|c|c|}
\hline Jam Kerja & Jumlah & $\begin{array}{c}\text { Persentase } \\
(\%)\end{array}$ \\
\hline × 7Jam/hari & 33 & 66 \\
\hline >7Jam/hari & 17 & 344 \\
\hline Total & 50 & 100 \\
\hline
\end{tabular}

Dari tabel 4.2 diatas menunjukkan bahwa pekerja yang tidak mengalami kelebihan jam kerja sebanyak 33 orang (66\%) dan pekerja yang mengalami kelebihan jam kerja sebanyak 17 orang(34\%).

\section{Analisis Bivariat}

\section{Table 4.3 Analisis Hubungan} Kelebihan Jam Kerja dengan yang tidak mengalami hipertensi sebanyak 43 orang (86\%) dan pekerja yang mengalami hipertensi sebanyak 7 orang $(14 \%)$.

Hasil penelitian didapatkan bahwa pekerja di PT. Astoria Bangun Perkasa Batam hanya $1 /$ /orang yang mengalami hipertensi. Ini hasil yang memuaskan

\section{Kejadian Hipertensi}

\begin{tabular}{|c|c|c|c|c|c|}
\hline \multirow{2}{*}{ Jam Kerja } & \multicolumn{2}{|c|}{$\begin{array}{c}\text { Hiperte } \\
\text { nsi }\end{array}$} & \multirow[t]{2}{*}{$\mathrm{F}$} & \multirow[t]{2}{*}{$\begin{array}{c}\mathrm{p} \\
\text { value }\end{array}$} & \multirow[t]{2}{*}{ OR } \\
\hline & + & - & & & \\
\hline $\begin{array}{l}\leq \\
7 \text { Jam/hari }\end{array}$ & 33 & 0 & 33 & \multirow[t]{3}{*}{0.001} & \multirow[t]{3}{*}{1,7} \\
\hline >7Jam/hari & 10 & 7 & 7 & & \\
\hline Total & 43 & 7 & 50 & & \\
\hline
\end{tabular}

Dari tabel 4.3 diatas menunjukan bahwa pekerja yang tidak mengalami hipertensi dan bekerja $\leq 7$ jam/hari sebanyak 33 orang $(66 \%)$, pekerja yang tidak mengalami hipertensi dan bekerja > 7 jam/hari sebanyak 10 orang (20\%) - Sedangkan tidak ada pekerjayang bekerja $\leq 7$ jam/hari yang mengalami hipertensi, dan pekerja yang mengalami hipertensi dan bekerja > 7 jam/hari sebanyak 7 orang (14\%).

Berdasarkan analisis dari hasil Chi-square nilai signifikansinya $p$ value sebesar 0,000. Dimana apabila $p$ value $<0,05 \mathrm{H}_{0}$ ditolak, maka terdapat hubungan yang signifikan antara kelebihan jam kerja dengan kejadian hipertensi pada pekerja PT. Astoria Bangun Perkasa Batam Tahun 2018. Hasil perhitungan Odd Ratio didapat hasil $\mathrm{OR}=1,700$ yang berarti pekerja yang mengalami kelebihan jam kerja 1,700 kali lebih beresiko mengalami hipertensi dibandingkan dengan pekerja yang tidak mengalami kelebihan jam kerja.

\section{PEMBAHASAN}

\section{Distribusi Kejadian Hipertensi}

Bedasarkan hasil penelitian dari 50 responden, diperoleh bahwa pekerja

yang membuktikan para pekerja PT. Astoria Bangun Perkasa sebagian besar sudah menjalani gaya hidup yang sehat dan paham akan bahaya hipertensi sehingga terhindar dari penyakit hipertensi

Berdasarkan hasil pengamatan peneliti sebagian pekerja PT. Astoria Bangun Perkasa Batam Tahun 2018 
terkena hipertensi yang disebabkan oleh kelebihan jam kerja dan kurangnya waktu istirahat bagi para pekerjaserta secara objektif menghubungkan timbulnya hipertensi dengan peningkatan kelebihan jam kerja. Banyak faktor yang dapat mengakibatkan hipertensi pada pekerja di PT. Astoria Bangun Perkasa selain jam kerja yang melebihi penetapan pemerintah mengenai jam kerja antara lain faktor stres yang dirasakan para pekerja akibat pekerjaan yang harus diselesaikan secepat mungkin dan dengan tekanan dari atasan yang dapat membuat pekerja semakin tertekan dalam pekerjaannya, faktor kebiasaan merokok yang terjadi dilingkungan para pekerja karena menurut mereka merokok dapat mengurangi stres yang mereka alami.

\section{Distribusi Kelebihan Jam Kerja}

Bedasarkan hasil penelitian dari 50 responden, diperoleh hasil pekerja yang bekerja $\leq 7 \mathrm{jam} /$ harisebanyak 33 orang $(66 \%)$, dan pekerja yang bekerja $>7 \mathrm{jam} /$ hari sebanyak 17 orang $(34 \%)$.

Hasil penelitian didapatkan bahwa tiga dari empat pekerja di PT. Astoria Bangun mengalami kelebihan jam kerja serta sebagian mengalami kurang istirahat dimana sesuai dengan riset yang dilakukan oleh ilmuan Henry Ford Hospital, Detroit menyebutkan bahwa orang-orang dengan gangguan tidur memiliki kemungkinan hipertensi (Anonym, 2015).

Hasil penelitian ini sejalan dengan penelitian oleh Business Roundtable (2012) dari 250 responden, didapatkan pekerja yang bekerja > 7 jam/hari untuk 6 hari kerja sebanyak 190 responden $(76 \%)$ dan pekerja yang bekerja $\leq 7$ jam/hari untuk 6 hari kerja sebanyak 60 responden (24\%).

Berdasarkan hasil pengamatan peneliti para pekerja PT. Astoria Bangun Perkasa mengalami kelebihan jam kerja disebabkan karna batas waktu penyelesaian proyeknya yangmendesak.

\section{Hubungan Kelebihan Jam Kerja dengan Kejadian Hipertensi}

Dari hasil penelitian didapatkan bahwa pekerja yang tidak mengalami hipertensi dan bekerja $\leq 7 \mathrm{jam} /$ hari sebanyak 33 orang (66\%), pekerja yang tidak mengalami hipertensi dan bekerja > 7 jam/hari sebanyak 10 orang (20\%). Sedangkan tidak ada pekerja yang mengalami hipertensi dan bekerja $\leq 7 \mathrm{jam} / \mathrm{hari}$, dan pekerja yang mengalami hipertensi dan bekerja > 7 jam/hari sebanyak 7 orang (34\%).

Jam kerja yang tinggi diduga menjadi faktor terjadinya hipertensi. Hal ini ditunjukkan pada penelitian Yang, dkk (2006) menunjukkan ada hubungan yang antara jam kerja dan kejadian hipertensi. Penelitian dengan studi cross sectional dan berdasarkan populasi ini menunjukkan bahwa lama jam kerja mempengaruhi pada kejadian hipertensi yang disebabkan stres kerja. Hal tersebut juga dipengaruhi oleh faktor lingkungan tempat bekerja, seperti paparan panas, debu, ataupun asap, sehingga jika terpapar dalam waktu yang lama akan dapat mengakibatkan stres kerja, sedangkan stres merupakan salah satu faktor risiko penyakit hipertensi. Penelitian tersebut menghasilkan OR $=1,29$ pada orang yang bekerja 50 jam per minggu.

Kesimpulan diatas dibuktikan dengan hasil uji bivariat dari analisis statistik Chi-Square dan hasil perhitungan data yang diolah dengan menggunakan bantuan komputerisasi didapatkan nilai signifikansinya $\mathrm{p}=$ 0,000angka tersebut menunjukkan angka yang signifikan karena nilai $p$ lebih kecil dibandingkan dengan taraf signifikansi $(\square)=5 \%(0,05)$ maka $\mathrm{H}_{1}$ nya diterima. Hasil perhitungan Odd Ratio ddidapat hasil $\mathrm{OR}=1,700$ yang 
berarti pekerja yang mengalami kelebihan jam kerja 1,700 kali lebih beresiko mengalami hipertensi dibandingkan dengan pekerja yang tidakmengalami kelebihan jam kerja. Jadi, dapat disimpulkan bahwa ada hubungan kelebihan jam kerja dengan kejadian hipertensi pada pekerja PT. Astoria Bangun Perkasa Batam tahun 2018 .

\section{KESIMPULAN DAN SARAN Kesimpulan}

Berdasarkan hasil penelitian yang dilakukan penulis di PT. Astoria Bangun Perkasa batam dengan jumlah responden sebanyak 50 orang dapat disimpulkan bahwa :

1. Sebagian besar pekerja PT. Astoria Bangun Perkasa Batam tidak mengalami kelebihan jam kerja $(66 \%)$.

2. Sebagian besar pekerja PT. Astoria Bangun Perkasa Batam tidak mengalami hipertensi ( $86 \%$ ).

3 . Terdapat hubungan yang signifikan antara kelebihan jam kerja dengan kejadian hipertensi ( $p=0,000)$. Pekerja PT. Astoria Bangun Perkasa yang mengalami kelebihan jam kerja memiliki resiko 1,700 kali lebih besar untuk mengalami hipertensi dibandingkan pekerja yang tidak mengalami kelebihan jam kerja.

\section{Saran}

1. Bagi PT. Astoria Bangun Perkasa diharapkan dapat mengontrol jam kerja pekerjanya sehingga tidak terjadi lagi kelebihan jam kerja dan diharapkan pada PT. Astoria Bangun Perkasa beserta pekerjanya mengetahui dan menyadari penyebab yang memicu terjadinya hipertensi dan tidak menganggap remeh penyakit hipertensi agar dapat memperkecil resiko terjadinya hipertensi dan meningkatkan kualitas hidup.

2. Bagi penelitian lain diharapkan dapat melakukan penelitian lanjutan dengan metode yang berbeda ataupun sama namun dengan jumlah sampel yang lebih banyak lagi dan tambahan variabel seperti faktor lain seperti merokok, stres, mengkonsumsi garam dan mengkonsumsi alkohol yang mempengaruhi terjadinya hipertensi.

3. Diharapkan agar PT. Astoria Bangun Perkasa dapat meningkatkan kualitas lingkungan yang menyenangkan sesuai dengan kebutuhan pekerja dalam memaksimalkan mutunya.

\section{DAFTAR PUSTAKA}

Aaronson, P. I. And Ward, J. P. T., 2010. At a Glance Sistem Kardiovaskular. Jakarta: Erlangga.

Adisu, Edytus. 2008. Hak Karyawan Atas Gaji dan Pedoman Menghitung. Jakarta: ForumSahabat.

American Heart Association, 2006. Overtime Working and Hypertension_2006

Anonym, 2015. Hypertension. Henry Ford Hospital

Bakri, S., Lawrence, G.S., 2008. Genetika Hipertensi. Dalam: Lubis, H.R., dkk., eds. 2008. Hipertensi dan Ginjal: Dalam Rangka Purna Bakti Prof. Dr. Harun Rasyid Lubis, Sp.PD-KGH. Medan: USU Press, 19-31.

Balitbang Kemenkes RI. 2007. Riset Kesehatan Dasar; RISKESDAS. Jakarta: Balitbang kemenkes RI.

Baradero, M., Wilfrid Dayrit, Yakobus Siswadi., 2008. Klien Gangguan Kardiovaskular. Jakarta: EGC.

Brown, J. E. et al. 2005. Nutrition Through The Life Cycle, $2^{\text {nd }}$ ed. Thomson Nadsworth. USA

Davey, Patrick. 2005. At a Glance Medicine. Jakarta: Erlangga.

Depkes RI. 2013. Infodatin: Hipertensi. Jakarta: Departemen 


\begin{tabular}{l|r|r}
\hline \multirow{2}{*}{ Jurnal Penelitian Kesmasy } & Vol. 2 No. 1 & Edition: May - October 2019 \\
\hline \multirow{2}{*}{ Received: 17 September 2019 } & http://ejournal.delihusada.ac.id/index.php/JPKSY & \\
\cline { 2 - 3 } & Revised: 01 October 2019 & Accepted: 15 October 2019 \\
\hline
\end{tabular}

kesehatan

http://www.depkes.go.id/downloa d.php?file =download/pusdatin/info datin/infodatin-hipertensi.pdf. 19 April 2015.

Dinas Kesehatan kota Batam. 2014. Prevalensi Hipertensi.

Gray, et al. 2005. Lecture Notes Kardiologi edisi 4. Jakarta: Erlangga Medical Series

Guyton A. C and J.E. Hall. 2007. Buku Ajar Fisiologi Kedokteran. Edisi 9. Jakarta: EGC.

Julius, S. 2008. Clinical implications of pathophysiologic changes in the midlife hypertensive patients. American Heart Journal, 122: 886891.

Kaplan, N. M., dan Stamler, J. 1996. Pencegahan Penyakit Jantung Koroner: Penatalaksanaan Praktis dari Faktor-faktor Resiko. Jakarta: EGC.

Kepmen Tenaga Kerja dan Transmigrasi No. 102/ Men/ VI/ 2004 Tentang Waktu Kerja Lembur dan Upah Lembur.

Kumar V, Cotran RS, Robbins SL. 2007. Buku Ajar Patologi. $7^{\text {nd }}$ ed, Vol 2. Jakarta : EGC.

Notoatmodjo, Soekidjo. 2012. Metodolog Penelitian Kesehatan. Jakarta: Rineka Cipta.

Malasari. (2008). Hubungan Tingkat Pengetahuan pasien dengan Pencegahan Kekambuhan Hipertensi di Grogol, Depok. Universitas Pembangunan Nasional

Ogedegbe G, Pickering T. Principles and techniques of blood pressure measurement. Cardiol Clin. 2010; 28(4): 571-86.

Pickering, T.G., Ogedegbe, G., 2008. Epidemiology of Hypertension. In: Fuster, V., et al., eds. Hurst's the Heart. Volume 2. 12th ed. USA: Mc Graw-Hill, 1551- 1565.

Price, Sylvia A dan Wilson, Lorrain M. 2005, Patofisiologi Konsep Klinis Proses- proses Penyakit, edisi 6, Jakarta: EGC.
Rahmouni K, Correia MLG, Haynes WG, Mark Al. Obesityassociated hypertension: New insights into mechanisms. Hypertension 2005; 45:9-14.

Sridianti. 2015. Pengaruh Alkohol pada Tekanan Darah. Diunduh pada tanggal 9 September 2015 dari

http://www.sridianti.com/pengar uh-alkohol-pada-tekanandarah.html

The Business Roundtable, 2012. Statement on Corporate Governance, Washington DC

UCSF Medical Centre. Risk Factors for High Blood Pressure (Hypertension). San Francisco

Undang-Undang Republik Indonesia Nomor 13 Tahun 2003 tentang Ketenagakerjaan.

World Health Organization. 2012. Classification of Hypertion. 